\title{
Moving up, feeling down: socioemotional health during the transition into college
}

\author{
Julie Skalamera Olson \\ julie.skalamera@utexas.edu
}

(Received July $2016 \quad$ Revised January 2017)
University of Texas at Austin, US

\section{Abstract}

Moving from high school to college is a critical juncture in socioemotional health, and how young people fare likely depends on their academic settings and experiences. To examine variation in trajectories of depressive symptomatology among a sample of US youth who transition from high school into college, this study applied growth mixture modeling to data from the National Longitudinal Study of Adolescent to Adult Health, which revealed multiple patterns of symptomatology over time that ranged from healthy to unhealthy. Adolescents appeared to have the healthiest trajectories when they experienced consistently competitive academic settings in high school and college. Overall, transitioning into college was a period of socioemotional vulnerability for some and wellbeing for others, but challenging curricula and contexts across this transition could differentiate between the two.

\section{Keywords}

Socioemotional well-being; depressive trajectories; college-going; academic context; curricular position

In the US, rates of college-going have reached unprecedented levels with increasing numbers of young people pursuing the economic, social, and health benefits of higher education (Goldin \& Katz, 2008; Mirowsky \& Ross, 2003). As youth flood into college and reach for the long-term returns to a degree, they move between distinct high school and college settings during a period of developmental sensitivity. Consistencies and disjuncture between these two sets of settings therefore have implications for their wellbeing beyond their academic prospects (Benner, 2011; Eccles et al., 1993). Indeed, collegegoing is likely to be a critical juncture in trajectories of socioemotional health during the early life course.

This study, therefore, uses a life-course framework to shed light on the role of the transition into college in shaping young people's socioemotional health. The first aim is to identify variation in wellbeing among college-going youth, which I do by classifying trajectories of depressive symptoms among collegegoers in the National Longitudinal Study of Adolescent to Adult Health (Add Health). The second aim is to examine how the settings and experiences of high school and college are related to this socioemotional variation, which I do by predicting socioemotional trajectories by the match or mismatch of academic settings and curricular experiences at each educational stage (defined by school competitiveness and pathways of science and math course-taking). In doing so, this study identifies the contexts in which socioemotional difficulties among college-goers may be most and least pronounced. The results inform efforts to encourage positive wellbeing among the increasingly diverse 
group of young people who access higher education in the US.

\section{Socioemotional variability and the transition to college}

Adolescence is a time of rapid change and growth, when individuals struggle to establish their identities (i.e., developing a sense of who they are and where they fit in the world) and, in the process, individuate from parents and set themselves up for adulthood (Kroger, 2007). This process has socioemotional implications, as individuals develop physically, socially, and psychologically at different rates and struggle with competing demands and expectations from peers and adults (Cavanagh, Riegle-Crumb \& Crosnoe, 2007). As young people seek to leave adolescence behind and enter adulthood-a developmental stage often referred to as emerging adulthood-they become financially independent, involved in intimate romantic relationships, and prepare for stable adult employment (e.g., Arnett, 2015). While navigating these transitions, a hallmark of this life course stage is that many youth will also complete high school and enter college (Johnson, Crosnoe, \& Elder, 2011). Their developmental trajectories and institutional pathways are therefore closely connected to each other in a two-way exchange (South, Haynie \& Bose, 2007; Staff \& Kreager, 2008).

This two-way exchange is closely aligned with the basic focus of life course theory, which is a valuable frame for understanding the transition into college. This perspective views transitions as specific points of change in status and/or setting that act as mechanisms of deflection and intensification in general trajectories of adjustment and functioning, the concrete periods in which life course trajectories are likely to change directions (Elder, 1998; George, 1993). The transition from high school into college is indeed a concrete change in status and setting, and, as such, is likely to be a critical period in which longterm educational trajectories take new shape. It is a short-term experience embedded in a long-term trajectory, and how young people fare during this short-term experience can create stability - or disjuncture - between past histories and future prospects. In socioemotional terms, how might the transition into college look? On average, individuals who go to college thrive. Other adolescents, conversely, may experience difficulties with the transition from high school to college. The pressure of the transition along with the demands of navigating a new social environment may lead to stress. Going to college often means leaving home, making new friends, and worrying about the future. Despite the promise of personal growth and the excitement of new opportunities, college-goers may fear failure. Even when these stressful and difficult experiences are comparatively short-term 'growing pains', they may have long term effects by influencing grade point average or coursework, for example. Overall, distress associated with college-going may shape the cumulative trajectories of adolescents over broader periods of time.

My first aim, therefore, is to highlight variation in how adolescents experience the transition into college. I use depressive symptomatology to capture socioemotional adjustment because such symptoms indicate difficulty during the transition. I hypothesise that adolescents will differ in their socioemotional health across this transition, such that some adolescents will suffer (defined by rising depressive symptomatology) while others will have stable trajectories.

\section{Academic setting and curricular position}

A major tenet of life course theory is that developmental trajectories (e.g., socioemotional adjustment) unfold within social contexts. Contexts such as institutional contexts like educational systems - provide opportunities for different experiences, place constraints on individual behaviour and relationships, introduce stressors and supports, and serve as sites for cultural socialisation into prevailing norms and values (Bronfenbrenner \& Morris, 1998). Thus, the transition into college can be better understood by anchoring it within such institutional contexts. The transition into college is one piece of a sequence of institutional experiences within the educational system. Consequently, it needs to be studied in relation to how the pieces of this sequence fit together, past and present. This sequence has multiple dimensions, including the school settings and the curricular experiences of young people over time. 
First, one aspect of the school setting concerns academic competitiveness - how achievementoriented and successful are the students in a given school? School-level influences not only during the transition to college but also pre-transition may encourage or prevent individuals from realising their educational capabilities. The courses adolescents take in high school are highly influenced by the school itself (Frank et al., 2008). Individuals in more competitive high schools, therefore, are more likely to develop skills that facilitate ability to thrive in any academic setting. Indeed, the effects of high school settings persist, and academic context and high school curriculum are predictive of bachelor degree completion (Adelman, 1999). Likewise, more selective colleges may generate more competitive environments that encourage focus in the classroom and motivation despite difficulties that the transition to college may present. No exposure to competitive and selective academic settings, on the other hand, may leave individuals unprepared to realise their academic capabilities or persisting through difficulties. Adolescents in these less competitive and selective environments during high school may take their education less seriously and may therefore experience distress upon transitioning to higher education. The potential importance of educational settings for socioemotional trajectories may, therefore, vary not only by high school or college context but also by how these contexts align.

Second, one aspect of curricular position concerns exposure to Science, Technology, Engineering and Mathematics (STEM) curricula that are often touted as positioning youth for socioeconomic mobility and security in the modern economy. The foundation for STEM is set with high school maths and science coursework, as courses in high school have implications for later educational experiences. Highlevel STEM coursework in high school is associated with college attendance and graduation in the US (Adelman, 1999; Schneider, Swanson, \& RiegleCrumb, 1997). These advanced courses are referred to as the STEM 'pipeline' (Burkham \& Lee, 2003), and US policy frequently directs efforts towards maintaining the progression of students through the pipeline. Beyond high school, research has shown STEM majors are a foundation for economic security after college and, notably, for academic anxiety in college (Schneider \& Keesler, 2007). Together, advanced math and science coursework in high school and STEM majors in college may prepare adolescents for the curricular demands of higher education and, ultimately, for highly favored employment in U.S. society, thereby having implications for wellbeing. If so, how high school and college curricular pathways intersect might also matter to socioemotional health. Having high-level curricular position in high school (as indicated by advanced math and science coursework) and a valued curricular focus in college (as indicated by declaration of a STEM major) may prevent individuals from experiencing distress during the transition from high school to college.

Whether considering academic settings or curricular pathways, the experiences of young people in high school or college likely matter, independently, to their adjustment during the transition into college. Yet, life course theory suggests that continuity and change in experiences between high school and college matters-in other words, do settings and experiences across high school and college match up or not? Certainly, there is likely to be consistency across levels, with students from more competitive high schools often going into more selective colleges and the math/science pipeline flowing into STEM sectors of higher education (Berryman, 1983). To the extent that consistency protects youth from having to adapt to a major disjuncture, youth whose high school and college settings and positions match up will be better able to adjust to college than those whose settings and positions do not. Match/mismatch matters above and beyond the pressures put forward by any one setting or position at any one time. For example, navigating a STEM major in a selective college may come with a great deal of expectation and stress for any student, but less so for students who came into this situation with advanced math/science credentials from a competitive high school. Thus, the match/mismatch between high school and college is a qualifier to the experience of college.

My second aim is, therefore, to identify who is at risk of distress during this transition based on their high school and college experiences and how the match (or mismatch) of academic setting and curricular position across high school and college may 
prevent (or facilitate) depressive symptoms. The hypothesis is that adolescents who have experienced a disjuncture (or mismatch) between the settings and/or curricula of their high schools and colleges will face more socioemotional difficulty than others.

\section{Methods}

\section{Data and sample}

Add Health is a nationally representative survey of US adolescents in secondary school that launched in 1994 with an in-school survey and followed adolescents into young adulthood (Harris et al., 2009). Schools included in the study were selected by region, urbanicity, school size, school type, and racial composition based on a stratified sampling design. Inschool data collection of 90,118 students in 132 schools had a census-like structure for each school, allowing for the aggregation of data across all respondents in a school. The in-school survey was also used to generate a nationally representative subsample of 20,745 students. This group was selected for Wave I in-home interviews in 1995 and was followed over the course of four waves. Wave II in-home interviews were conducted in 1996 and excluded participants who were Wave $I$ in their last year of secondary school. In-home interviews were also conducted in 2001-2002 and 2007-2008 for Wave III and Wave IV, respectively. As part of the companion Adolescent Health and Academic Achievement (AHAA) study, 90\% of the Wave III participants signed a transcript release form to grant access to their high school transcripts (Muller et al., 2007).

Prior to higher education (e.g., college), students in the US complete 12 years of schooling. Students begin primary school around age six and complete five to six years before starting secondary school. Secondary schools in the US have two programs: middle school (or junior high school) and high school, the latter of which is generally years nine to 12. Add Health surveyed students in both middle and high school, but the analytical sample for this study included only adolescents who were in high school at Wave I such that this paper captures only the educational transition from high school to college (rather than from middle to high school). The analytical sample was further restricted to students who had enrolled in either a two-year or four-year college after graduating from high school, persisted through Wave III, and had valid sampling weights. Youth who missed Wave II but came back into the study for Wave III were excluded given that they would be systematically missing on measures of depressive symptomatology necessary for estimation of socioemotional trajectories. Approximately 6,000 adolescents in the Add Health sample were not in high school at Wave I; of these, about 8,000 did not enroll in college after high school graduation. An additional 2,000 respondents did not have valid Wave III sampling weights, which included respondents who were excluded from Wave II data collection. Together, therefore, these filters resulted in a sample of 4,468 adolescents. Respondents in the final analytic sample were in year 10 of schooling ( $M$ Wave I grade $=10.2, S D=0.9$ ) such that, on average, the sample went to college two years after Wave I interview.

\section{Measures}

Depressive symptomatology. Add Health included a modified Center for Epidemiologic Studies-Depression scale in all waves (Pereira, Deeb-Sossa, Harris \& Bollen, 2005). Youth reported the frequency of nine feelings in the past week (e.g., "You felt that you could not shake off the blues, even with help from your family and your friends," "You felt sad"). Responses, which ranged from 0 (never or rarely) to 3 (most of the time or all of the time), were summed into a 27-point scale.

Academic setting. For high school, academic setting was operationalised with a standardised composite variable ('academic pressure') based on the school means (aggregated from all individual responses in the school on the in-school survey) of GPA (standard four-point scale), maths/science enrollment, and educational expectations (likelihood the student will graduate from college) as well as the administrator report of the percentage of seniors who go to college (Crosnoe, Riegle-Crumb \& Muller, 2007). This school-level measure is akin to measures in the educational literature gauging the emphasis on and pressure for achievement in schools (Shouse, 1996). Each item in the composite variable was standardised, and the final scale was the mean of the four $z$-scores (range of -1.37 to 1.48 ). For post- 
secondary institutions, academic setting was operationalised with a selectivity variable provided by the AHAA team. Based on the SAT scores of incoming students in each institution, it ranged from 1 to 20, with a score of 1 indicating the most academically selective institutions that ranked in the top $5 \%$, and a score of 20 representing the least academically selective institutions that ranked in the bottom $5 \%$ in terms of median SAT scores (Riegle-Crumb, Muller, Grodsky, Langenkam \& Pearson, 2008). To gauge transitional matches and mismatches, the two academic setting variables were dichotomised and cross-classified. The high school variable - based on z-scores - was dichotomised at one-half standard deviation above the mean score to indicate low versus high competitiveness. The college variable was also dichotomised at the one-half standard deviation above the mean score to indicate low versus high selectivity. Values on the two variables were combined to create four categories: high competitiveness to high selectivity, high to low, low to high, and low to low. Low to low was the reference used in analyses.

Curricular position. Curricular position was operationalised by maths and science coursework across the transition from high school to college. Mathematics and science enrollment in American secondary education is largely standardised into a hierarchy of less to more demanding classes. The ordinal maths and science variables available from the AHAA transcript data captured this hierarchical pattern of course-taking (Riegle-Crumb et al, 2008). Measured as the highest point reached in high school, the math and science coursework variables ranged from 0 (no maths) to 9 (calculus) in maths and 0 (no science) to 6 (physics), respectively. For college curricular position, a binary STEM major variable (1 = science, technology, engineering, or math major, $0=$ all other majors) was created based on self-reports of major. Majors were categorised as STEM or not-STEM using the degree program list maintained by the Department of Homeland Security. Again, these variables were dichotomised and cross-classified. Maths/science coursework measures were dichotomised at completion of both Algebra II and chemistry or higher to designate advanced coursework that has been shown to be most predictive of college preparedness (Adelman, 2006).
This measure was combined with the college STEM variable to create four categories: went from advanced high school maths/science coursework into a STEM college major, advanced to non-STEM, nonadvanced to STEM, and non-advanced to non-STEM). Non-advanced to non-STEM was the reference used in analyses.

Covariates. Several controls accounted for sociodemographic position: gender ( $1=$ male), Wave I age, race/ethnicity (non-Hispanic white, non-Hispanic black, non-Hispanic Asian, Hispanic, and other/multiracial), family structure ( 1 = lived with both biological parents at Wave I, $0=$ other family form), and parent education (an ordinal variable ranging from 1 , less than high school, to 5, post-college degree). Control variables were also measured to account for the broader institutional contexts in which students' academic settings and curricular positions were measured. To gauge general (non-maths/sciencespecific) status in high school, an honours English variable was constructed based on the number of honors English courses a respondent took in high school (range: 0 to 6), and cumulative high school GPA (on a 4.0 scale) at the end of school was measured, both based on transcript data. Additional school level controls were drawn from the in-school survey and included school sector (private versus public), the school size (in hundreds), the proportion of students with at least one college-going parent, the proportion of high school seniors enrolled in college preparatory classes, and the proportion of the high school students that identified as white. A dichotomous variable indicated whether the college that the respondent attended was a private institution (versus public).

\section{Analytical strategy}

The first step was to identify variation in trajectories of depressive symptomatology among college-goers as they transition from high school to college. Growth mixture modeling (GMM) is a type of structural equation model estimated in Mplus (Muthén \& Muthén, 1998-2008) that identifies major heterogeneities in growth curves in a sample. This statistical technique is based on the theory that several categories of trajectories may occur within a population. Here, it produced a categorical variable grouping cases according to the various types of 
trajectories of depressive symptomatology followed across Waves I, II, and III. The appropriate number of categories (or classes) was determined through several criteria including a log-likelihood test, Bayesian information criteria (BIC), and sample size adjusted BIC (ABIC).

Once GMM identified classes, the second step was to estimate the association of the match/mismatch of academic setting and curricular position with categories of socioemotional trajectories. Because four trajectories were identified, multinomial logistic regression in Stata (StataCorp, 2011) was used to predict trajectory by academic setting variables, curricular position variables, and their match/mismatch dummy variables, controlling for all measured covariates. Missing data were estimated with multiple imputation and longitudinal sampling weights were applied to all models. Additionally, all analyses adjust standard errors to account for the clustering of adolescents in schools, per the Add Health sampling design.

\section{Results}

\section{Trajectories of depressive symptoms among} college-goers

To test my first hypothesis and explore variation in the socioemotional health of adolescents transitioning from high school to college, GMM identified four main classes of depressive symptomatology across Waves I through III. Table 1 provides the criteria used to make this determination, and Figure 1 shows the trend lines of the classes. For log-likelihood, BIC, and ABIC measures of fit, smaller absolute values indicate better model fit; thus, the relative change from the $k$-class to $k$-1-class is important in assessing fit. For the Lo-Mendell Rubin (LMR) adjusted likelihood ratio test, a significant $p$ value suggests that the $k$-class model is better fitting than the $k$-1-class model. In this case, the four class model was the best fit of the data according to the relative changes in log-likelihood, BIC, and $A B I C$ values and LMR $p$-value. The four identified trajectories also presented substantively meaningful and useful classes.

[Table 1. GMM criteria for class determination

\begin{tabular}{|c|c|c|c|c|c|}
\hline & 1 Class & 2 Classes & 3 Classes & 4 Classes & 5 Classes \\
\hline Log-likelihood & -36024.102 & -35520.757 & -35271.334 & -35088.191 & -35019.651 \\
\hline \# parameters & 8 & 11 & 14 & 17 & 20 \\
\hline $\mathrm{BIC}$ & 72115.443 & 71133.965 & 70660.335 & 70319.261 & 70207.396 \\
\hline $\mathrm{ABIC}(\mathrm{AIC})$ & 72064.205 & 71063.514 & 70570.669 & 70210.381 & 70079.302 \\
\hline LMR $p$-value & & 0.0002 & 0.0087 & 0.0072 & 0.6188 \\
\hline Entropy & & 0.919 & 0.859 & 0.844 & 0.826 \\
\hline Distribution & & $\begin{array}{l}7.09 \%, \\
92.91 \%\end{array}$ & $\begin{array}{l}84.00 \%, \\
7.01 \%, \\
9.00 \%\end{array}$ & $\begin{array}{l}2.89 \%, \\
16.81 \%, \\
74.51 \%, \\
5.80 \%\end{array}$ & $\begin{array}{l}18.30 \%, \\
68.44 \%, \\
3.81 \%, \\
2.78 \%, \\
6.68 \%\end{array}$ \\
\hline
\end{tabular}

Note: $n=4,468$ 
Figure 1. Socioemotional trajectories across the transition to college determined by GMM

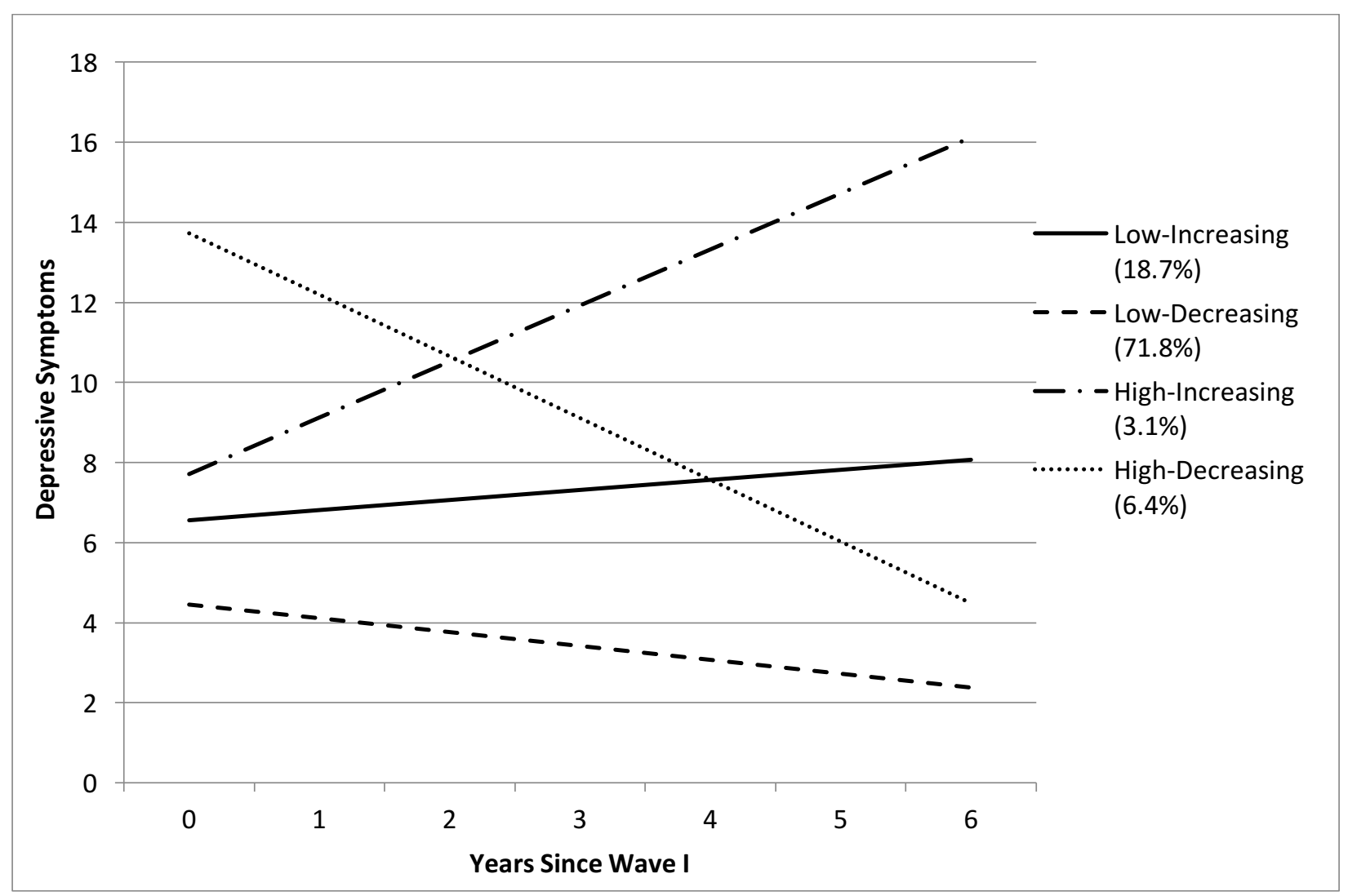

Note: $n=4,468$; transition to college occurred 1-4 years after Wave I interview

The four classes included adolescents with moderate levels of depressive symptoms that increased slightly during the transition period (labeled Slight-Increasing), those with consistently low levels of symptoms that saw some decline during this transition period (labeled Low-Decreasing), those with moderate levels of depressive symptoms in high school that increased sharply over the transition period (labeled Sharp-Increasing), and those with high levels of symptoms that decreased during this transition period (labeled High-Decreasing). The majority group was the Low-Decreasing class, suggesting that approximately $70 \%$ of adolescents who move from high school to college fared quite well across this transition period. Another $20 \%$ of adolescents belonged to the Slight-Increasing trajectory, experiencing some heightened distress. The third trajectory, the Sharp-Increasing class, represented only approximately $3 \%$ of the adolescents in the sample, but it was particularly concerning given the troubling rise in distress experienced across the transition into college. The High-Decreasing trajectory, on the other hand, comprised $6 \%$ of the adolescents in the sample who had poor socioemotional health in high school that improved as they moved into college. In sum, I found support for my first hypothesis that adolescents will differ in several ways in their socioemotional health across the transition to college, such that some adolescents will suffer (defined by rising depressive symptomatology) as they make this transition while others will have stable trajectories across this period. 
To understand the composition of these categories of socioemotional trajectories, Table 2 presents descriptive statistics. Variation in academic context and curricular position can be seen across classes. In terms of academic context, $24 \%$ of the LowDecreasing class, for example, moved from highly competitive high schools to highly selective colleges as compared to only $14 \%$ of the High-Decreasing class. The Slight-Increasing, Sharp-Increasing and High-Decreasing classes had higher proportions of youth in uncompetitive to non-selective schools (37$44 \%)$, whereas the Low-Decreasing class had the lowest proportion of students in this school-tocollege pattern (31\%). In terms of curricular position, nearly $6 \%$ of the Low-Decreasing class moved from advanced maths/science in high school to STEM major in college compared to less than $1 \%$ of the Sharp-Increasing class. The High-Decreasing class had the highest proportion of youth who were not in advanced maths/science in high school and not in STEM in college (63\%) compared to the LowDecreasing class, which contained the lowest proportion of young people following this pattern (49\%). 
Table 2. Descriptive statistics by depressive trajectory

\begin{tabular}{|c|c|c|c|c|c|c|c|c|}
\hline \multirow{2}{*}{ Depressive symptoms } & \multicolumn{2}{|c|}{$\begin{array}{c}\text { Slight-Increasing } \\
n=861 \\
\text { Mean (SD) } / \% \\
\end{array}$} & \multicolumn{2}{|c|}{$\begin{array}{c}\text { Low-Decreasing } \\
n=3,199 \\
\text { Mean (SD) } / \%\end{array}$} & \multicolumn{2}{|c|}{$\begin{array}{c}\text { Sharp-Increasing } \\
\qquad n=145 \\
\text { Mean (SD) } \%\end{array}$} & \multicolumn{2}{|c|}{$\begin{array}{c}\text { High-Decreasing } \\
n=263 \\
\text { Mean (SD)/ \% }\end{array}$} \\
\hline & & & & & & & & \\
\hline Wave I & 6.91 & $(3.80)$ & 4.52 & (3.11) & 7.94 & (5.17) & 14.38 & $(3.42)$ \\
\hline Wave II & 7.05 & (3.96) & 4.38 & (3.17) & 8.43 & $(4.56)$ & 12.99 & (3.93) \\
\hline Wave II & 8.54 & $(1.80)$ & 2.38 & (1.79) & 16.28 & $(2.58)$ & 4.59 & $(2.50)$ \\
\hline \multicolumn{9}{|l|}{ Academic context } \\
\hline High school competitiveness & -0.04 & $(0.54)$ & 0.09 & $(0.57)$ & 0.02 & $(0.50)$ & -0.01 & $(0.49)$ \\
\hline College selectivity & 11.41 & $(4.11)$ & 10.55 & (4.09) & 11.18 & (3.73) & 12.09 & $(4.10)$ \\
\hline \multicolumn{9}{|l|}{ Match/mismatch of academic context } \\
\hline High competitive to high selective & 18.12 & & 24.20 & & 19.31 & & 13.69 & \\
\hline High competitive to low selective & 5.23 & & 4.94 & & 5.52 & & 6.08 & \\
\hline Low competitive to high selective & 37.75 & & 39.79 & & 38.62 & & 36.50 & \\
\hline Low competitive to low selective & 38.91 & & 31.07 & & 36.55 & & 43.73 & \\
\hline \multicolumn{9}{|l|}{ Curricular position } \\
\hline Cumulative math coursework & 6.56 & $(1.63)$ & 6.96 & $(1.53)$ & 6.57 & $(1.50)$ & 6.50 & $(1.60)$ \\
\hline Cumulative science coursework & 4.65 & $(1.09)$ & 4.86 & $(1.06)$ & 4.59 & (1.09) & 4.48 & $(1.15)$ \\
\hline STEM major & 6.39 & & 7.60 & & 2.76 & & 3.80 & \\
\hline \multicolumn{9}{|l|}{ Match/mismatch of curricular position } \\
\hline Advanced math/science to STEM & 4.30 & & 5.53 & & 0.69 & & 2.28 & \\
\hline Advanced math/science to not STEM & 35.54 & & 43.61 & & 35.86 & & 33.08 & \\
\hline Not advanced math/science to STEM & 2.09 & & 2.06 & & 2.07 & & 1.52 & \\
\hline Not advanced math/science to not STEM & 58.07 & & 48.80 & & 61.38 & & 63.12 & \\
\hline
\end{tabular}


Table 2, continued.

\begin{tabular}{|c|c|c|c|c|c|c|c|c|}
\hline Sociodemographic covariates & \multicolumn{2}{|c|}{$\begin{array}{c}\text { Slight-Increasing } \\
\qquad n=861 \\
\text { Mean (SD) } / \%\end{array}$} & \multicolumn{2}{|c|}{$\begin{array}{c}\text { Low-Decreasing } \\
n=3,199 \\
\text { Mean (SD) } / \%\end{array}$} & \multicolumn{2}{|c|}{$\begin{array}{l}\text { Sharp-Increasing } \\
\qquad n=145 \\
\text { Mean (SD)/ \% }\end{array}$} & \multicolumn{2}{|c|}{$\begin{array}{l}\text { High-Decreasing } \\
n=263 \\
\text { Mean (SD) } / \%\end{array}$} \\
\hline Age & 15.98 & $(1.06)$ & 15.96 & $(1.10)$ & 15.89 & $(1.07)$ & 16.13 & $(1.00)$ \\
\hline Parent education & 3.08 & $(1.25)$ & 3.38 & $(1.22)$ & 3.16 & $(1.23)$ & 3.24 & $(1.28)$ \\
\hline Two-bio parent household & 58.42 & & 64.83 & & 55.17 & & 55.51 & \\
\hline Male & 44.60 & & 47.11 & & 28.28 & & 31.56 & \\
\hline \multicolumn{9}{|l|}{ Race/ethnicity } \\
\hline Non-Hispanic white & 44.13 & & 54.92 & & 40.69 & & 47.91 & \\
\hline Non-Hispanic black & 19.16 & & 17.85 & & 27.59 & & 17.87 & \\
\hline Hispanic & 17.65 & & 14.57 & & 16.55 & & 16.35 & \\
\hline Non-Hispanic Asian & 13.47 & & 8.03 & & 7.59 & & 13.31 & \\
\hline Other/ multi-racial & 5.57 & & 4.63 & & 7.59 & & 4.56 & \\
\hline \multicolumn{9}{|l|}{ School covariates } \\
\hline HS honors English & 0.80 & $(1.29)$ & 0.95 & $(1.41)$ & 0.85 & $(1.34)$ & 0.81 & $(1.32)$ \\
\hline HS cumulative GPA & 2.75 & $(0.70)$ & 2.93 & $(0.68)$ & 2.80 & (0.69) & 2.69 & $(0.74)$ \\
\hline HS private & 6.97 & & 9.85 & & 7.59 & & 4.56 & \\
\hline HS size (hundreds) & 14.18 & (8.39) & 13.33 & (8.24) & 15.67 & $(7.92)$ & 13.83 & (7.30) \\
\hline HS proportion college-going parents & 0.41 & $(0.15)$ & 0.43 & $(0.16)$ & 0.42 & $(0.14)$ & 0.40 & $(0.13)$ \\
\hline HS percentage college-prep seniors & 58.12 & $(26.76)$ & 60.38 & $(26.69)$ & 58.99 & $(26.25)$ & 57.87 & $(23.15)$ \\
\hline HS racial composition (proportion white) & 0.46 & $(0.34)$ & 0.52 & $(0.33)$ & 0.44 & $(0.34)$ & 0.47 & $(0.34)$ \\
\hline College private & 9.64 & & 12.57 & & 10.34 & & 9.51 & \\
\hline
\end{tabular}

Note: $n=4,468$ 
Academic setting, curricular position, and socioemotional trajectory

To accomplish my second aim and to identify who is at risk for distress during this transition based on their high school and college experiences, the first step was to determine how academic setting and curricular position in high school and college were associated with socioemotional trajectory. The initial multinomial logistic regression to predict membership in these four classes therefore included academic setting and curricular position variables from high school and college, along with the full set of sociodemographic and school covariates (see Table 3, with the Low-Decreasing class as the reference). Competitive high school settings $(p<.05)$ predicted lower risk of membership in the Slight-Increasing class (vs. Low-Decreasing), advanced maths coursework during the high school years $(p<.05)$ predicted lower risk of membership in the SharpIncreasing class (vs. Low-Decreasing), and advanced science coursework $(p<.05)$ predicted lower risk of membership in the High-Decreasing (vs. LowDecreasing). High school settings and curricular pathways were, therefore, associated with socioemotional trajectories across the transition to college independent of college settings and curricular pathways. College setting and curricular variables were not significantly associated with class membership.

Table 3. Multinomial logistic regression predicting class membership by academic setting and curricular position

\begin{tabular}{lccc}
\hline & $\begin{array}{c}\text { Slight-Increasing } \\
R R R(S E)\end{array}$ & $\begin{array}{c}\text { Sharp-Increasing } \\
R R R(S E)\end{array}$ & $\begin{array}{c}\text { High-Decreasing } \\
R R R(S E)\end{array}$ \\
\hline Academic setting & & & \\
High school competitiveness & $0.625 *$ & 1.053 & 0.921 \\
& $(0.114)$ & $(0.465)$ & $(0.272)$ \\
College selectivity & 0.989 & 0.987 & 1.059 \\
& $(0.018)$ & $(0.044)$ & $(0.043)$ \\
Curricular position & & & \\
Maths coursework & 0.954 & $0.786 *$ & 1.060 \\
& $(0.048)$ & $(0.093)$ & $(0.067)$ \\
Science coursework & 0.985 & 0.973 & $0.806 *$ \\
& $(0.059)$ & $(0.153)$ & $(0.078)$ \\
STEM major & 0.945 & 0.767 & 0.555 \\
& $(0.210)$ & $(0.599)$ & $(0.292)$ \\
\hline
\end{tabular}

Note: $n=4,468$; relative risk ratios presented $(R R R)$ with standard errors (SE); reference group for socioemotional trajectory is Low-Decreasing; models control for sociodemographic covariates including age, parent education, family structure, gender, race/ethnicity; models also control for school covariates including high school English course-taking, GPA, sector, size, college-going parents, college-prep courses for seniors, and racial composition, along with college sector; ${ }^{*} p<.05$, ** $p<.01, * * * p<.001$. 
Having examined the independent role of high school and college settings and curricular positions in trajectories of depressive symptomatology, the next step was to consider their dual or synergistic roles; in other words, exploring matches and mismatches across high school and college (see Table 4, with the Low-Competition/Less-Selective group as the reference for setting and Not Advanced/Not STEM group as reference for curriculum but all pairwise comparisons estimated in ancillary models). In terms of academic setting, the consistency or disjuncture between high and low demands across high school to college was not significantly associated with socioemotional trajectory. Turning to curricular position, consistency across the two sides of the transition seemed to matter. Specifically, as compared to adolescents who moved from low-level math and science in high school to non-STEM majors in college, adolescents who transitioned from advanced maths and science curriculum in high school to STEM majors in college were significantly less likely to be in the Sharp-Increasing $(p<.001)$ or High-Decreasing $(p<.05)$ classes of depressive symptomatology (relative to the Low-Decreasing class). Adolescents in more challenging curricula appeared to be somewhat protected against trajectories of socioemotional health characterised by troubling rises in depressive symptoms and against those characterised by heightened distress that improves across the transition to college. 
Table 4. Multinomial logistic regression predicting class membership by match/mismatch of academic setting and curricular position

\begin{tabular}{|c|c|c|c|c|c|c|c|c|}
\hline & $\begin{array}{c}\text { Slight- } \\
\text { Increasing } \\
R R R(S E) \\
\end{array}$ & $\begin{array}{c}\text { Sharp- } \\
\text { Increasing } \\
R R R(S E)\end{array}$ & $\begin{array}{c}\text { High- } \\
\text { Decreasing } \\
R R R(S E) \\
\end{array}$ & $\begin{array}{c}\text { Slight- } \\
\text { Increasing } \\
R R R(S E)\end{array}$ & \multicolumn{2}{|c|}{$\begin{array}{c}\text { Sharp- } \\
\text { Increasing } \\
R R R(S E)\end{array}$} & \multicolumn{2}{|c|}{$\begin{array}{c}\text { High- } \\
\text { Decreasing } \\
R R R(S E)\end{array}$} \\
\hline \multicolumn{9}{|l|}{ Academic setting } \\
\hline \multirow[t]{2}{*}{ High competitive to high selective } & 1.021 & 0.806 & 0.786 & & & & & \\
\hline & $(0.233)$ & $(0.425)$ & $(0.305)$ & & & & & \\
\hline \multirow[t]{2}{*}{ High competitive to low selective } & 1.011 & 0.887 & 1.221 & & & & & \\
\hline & $(0.237)$ & $(0.490)$ & $(0.505)$ & & & & & \\
\hline \multirow[t]{2}{*}{ Low competitive to high selective } & 0.899 & 0.718 & 0.817 & & & & & \\
\hline & $(0.141)$ & $(0.251)$ & $(0.253)$ & & & & & \\
\hline \multicolumn{9}{|l|}{ Curricular position } \\
\hline \multirow{2}{*}{\multicolumn{2}{|c|}{ Advanced maths/science to STEM }} & & & 0.832 & 0.006 & $* * *$ & 0.294 & \\
\hline & & & & $(0.203)$ & $(0.006)$ & & $(0.181)$ & \\
\hline \multirow{2}{*}{\multicolumn{2}{|c|}{ Advanced maths/science to not STEM }} & & & 0.990 & 0.739 & & 0.700 & \\
\hline & & & & $(0.126)$ & $(0.222)$ & & $(0.175)$ & \\
\hline \multirow{2}{*}{\multicolumn{2}{|c|}{ Not advanced maths/science to STEM }} & & & 1.176 & 2.587 & & 0.734 & \\
\hline & & & & $(0.403)$ & $(2.247)$ & & $(0.631)$ & \\
\hline
\end{tabular}


In sum, I did not find support for my second hypothesis that a disjuncture (or mismatch) between the settings and/or curricula of their high schools and colleges will be associated with more distress. Instead, results suggest that more academic challenges in science and maths course-taking across high school - and consistency in these challenges over the transition to college - was associated with being in latent classes of depressively symptomatology that suggested better socioemotional health across the transition into college. I ran sensitivity analyses testing the consistency of my results with other methods by regressing the probabilities of membership in each latent class on educational attainment and all covariates (Bray, Lanza, \& Tan, 2015). Results (not shown) are consistent with the findings presented. One slight exception is that cumulative maths sequence was only marginally significantly associated with reduced probability of membership in the SharpIncreasing (compared to a significant association at $p$ $<.05$ in Table 3).

\section{Discussion}

The pool of American youth transitioning from high school to college has expanded, and more adolescents than ever are attempting to earn a college degree (Jacob \& Wilder, 2010; Reynolds, Stewart, MacDonald \& Sischo, 2006). In turn, the pool of college-goers is increasingly diverse. Thus, advantages associated with college-going are likely to mirror the heterogeneity of incoming students. Indeed, when college-goers interact with new academic institutions and face new challenges in the classroom, some may thrive and others may falter. Socioemotional distress during the transition may, in turn, launch adolescents on trajectories of diminished wellbeing. The goals of this study, therefore, were to identify variation in trajectories of socioemotional health across the transition from high school to college and to determine how consistency or disjuncture across academic settings and curricular position helped to explain this variation.

Although many adolescents did quite well when transitioning from high school into college with greater than $70 \%$ showing a healthy socioemotional trajectory, others seemed to be vulnerable during this transitional period. In fact, greater than $20 \%$ of student experienced increases in depressive symptoms across the transition. Further analyses suggested that, independent of college setting or curriculum, the academic competitiveness of an adolescent's high school and their math and science course-taking in high school were associated with trajectories of socioemotional health as he or she transitioned into college. Consistency in maths and science curriculum across high school to college, furthermore, appeared to protect adolescents from trajectories of socioemotional distress during this transition. The match or mismatch of the academic setting, on the other hand, was not associated with socioemotional trajectories. These results are intriguing and raise two important questions.

First, why were curricular matches more important than mismatches in predicting trajectories of depressive symptomatology during the transition to college? Perhaps students enrolled in more science and maths courses may be more capable of handling the transition to higher education due to educational skills stressed in these secondary school classrooms. This explanation is consistent with previous work showing that high school setting influences coursetaking in college, which, in turn, predicts bachelor degree completion (Frank et al., 2008; Adelman, 1999) and with previous work showing that precollegiate academic performance is associated with majoring in STEM (Rask, 2010). Increased expectations of student performance and high requirements for maths and science coursework, therefore, may support socioemotional health during the transition into college. Such possibilities need to be considered more fully by building on what I have done here. Persistence through college, for example, was not considered. Although some research suggests that adolescents who enter college and drop-out do not suffer long-term emotional distress (Reynolds \& Baird, 2010), our research highlights a subset of adolescents for whom college-going is associated with poor socioemotional health. We need to know more about how the match in curriculum across the transition to college might matter for the socioemotional health of those who do not persist.

Second, why was consistency or disjuncture across academic setting not related to trajectories of socioemotional wellbeing? Perhaps going to college is 
less about the academic setting from which one comes and more about the relationships and support that individuals have to deal with an important life course transition. When faced with risk, youth may draw on protections that buffer against that risk, so that two youth in the same situation fare quite differently. This buffering could apply to socioemotional adjustment during the transition into college in general or more particularly to the role of match/mismatch in shaping adjustment during this transition (Steinberg, Brown \& Dornbusch, 1996). Possibly self-selection into college occurs. Adolescents with better developed socioemotional coping skills may be more likely to go to college and also more likely to experience a smooth transition. Likewise, self-selection into academic settings and curricular pathways may also occur. For example, youth on increasing trajectories of depressive symptoms in high school who transition into college may be less likely to transition from advanced maths or science to a STEM major. Future studies need to better account for this potential bias, including by leveraging fixed effects and instrumental variable designs. Further, while the focus of the current study is on adolescents who enter college after high school, non-college-goers may face risks for socioemotional health when making similar transitions into work or family life at this developmental stage. More broadly, therefore, research should consider how settings and experiences that match or mismatch across various simultaneous transitions may be associated with socioemotional risks for a more diverse group of young people.
An additional limitation of the current study was the potential for measurement error in the academic setting and curricular position variables. Sensitivity analyses considered different thresholds for the dichotomisation of academic settings. When high school competitiveness and college selectivity were dichotomised at one standard deviation above the mean, multinomial logistic regression results suggested that youth in highly competitive high schools who transition to highly selective colleges were at significantly lower risk of membership in Slight-Increasing and High-Decreasing trajectories. Using this dichotomisation, however, resulted in an insufficient number of respondents in the high competitive to low selective environments.

Given that earning a college degree has lifelong social, economic, and health returns and given how many adolescents attend college in pursuit of these returns (Mirowsky \& Ross, 2003), studying what happens during the transition into college is important. This importance extends beyond the economic and educational literatures into research on adolescent health, and this study contributes to that goal. Understanding which adolescents are best positioned to capitalise on advantages (or reverse disadvantages) of their early years and elucidating health implications of these transitional experiences can promote the future prospects of today's youth not only by encouraging adolescents' more immediate wellbeing, but also by comprehending how educational influences and transitions contribute to longer-term health and mortality.

\section{Acknowledgements}

This research uses data from Add Health, a program project directed by Kathleen Mullan Harris and designed by J. Richard Udry, Peter S. Bearman, and Kathleen Mullan Harris at the University of North Carolina at Chapel Hill, and funded by grant P01-HD31921 from the Eunice Kennedy Shriver National Institute of Child Health and Human Development, with cooperative funding from 23 other federal agencies and foundations. Special acknowledgment is due Ronald R. Rindfuss and Barbara Entwisle for assistance in the original design. Information on how to obtain the Add Health data files is available on the Add Health website (http://www.cpc.unc.edu/addhealth). No direct support was received from grant P01-HD31921 for this analysis. The author acknowledges the generous support of grants from the National Institute of Alcohol Abuse and Alcoholism (R21AA020045-01) and the National Institute of Child Health and Human Development (R24 HD042849) to the Population Research Center, University of Texas at Austin. This research also received support from the grant, 5 T32 HD007081, Training Program in Population Studies, awarded to the Population Research 
Center at The University of Texas at Austin by the Eunice Kennedy Shriver National Institute of Child Health and Human Development.

\section{References}

Adelman, C. (1999). "Answers in the tool box: Academic intensity, attendance patterns, and bachelor's degree attainment." Washington, DC: Government Printing Office. U.S. Department of Education, Office of Educational Research and Improvement.

Adelman, C. (2006). The toolbox revisited: Paths to degree completion from high school through college. Washington, DC: U.S. Department of Education.

$<$ www.ed.gov/rschstat/research/pubs/toolboxrevisit/index.html>.

Arnett, J.J. (2015). Emerging adulthood: The winding road from the late teens through the twenties. New York, NY: Oxford University Press. $2^{\text {nd }}$ ed. https://doi.org/10.1093/oxfordhb/9780199795574.013.9

Benner, A.D. (2011). "Latino adolescents' loneliness, academic performance, and the buffering nature of friendships." Journal of Youth and Adolescence 40:556-67. https://doi.org/10.1007/s10964-010-9561-2

Berryman, S. E. (1983). Who will do science? Trends, and their cause in minority and female representation among holders of advanced degrees in science and mathematics. New York, NY: Rockefeller Foundation.

Bray B.C., Lanza S.T., Tan X. (2015). "Eliminating bias in classify-analyze approaches for latent class analysis." Structural Equation Modeling 22: 1-11. https://doi.org/10.1080/10705511.2014.935265

Bronfenbrenner, U., \& Morris, P. (1998). "The ecology of developmental processes." In W. Damon (Ed.), Handbook of child psychology, Vol. 1 (pp.993-1028). New York: Wiley.

Burkam, D.T., and Lee, V.E. (2003). "Mathematics, foreign language, and science coursetaking and the Nels:88 transcript data." NCES 2003-01, Washington, DC: U.S. Department of Education, National Center for Education Statistics.

Cavanagh, S.E., Riegle-Crumb, C., \& Crosnoe, R. (2007). "Puberty and the education of girls." Social Psychology Quarterly 70:186-98. https://doi.org/10.1177/019027250707000207

Crosnoe, R., Riegle-Crumb, C., and Muller, C. (2007). "Gender, Self-Perception, and Academic Problems in High School." Social Problems 54: 118-138. https://doi.org/10.1525/sp.2007.54.1.118

Eccles, J.S., Midgley, C., Wigfield, A., Buchanan, C.M., Reuman, D., Flanagan, C., and Iver, D.M. (1993). "Development during adolescence: The impact of stage-environment fit on young adolescents' experiences in schools and in families." American Psychologist 48: 90-101. https://doi.org/10.1037/0003-066X.48.2.90

Elder, G.H., Jr. (1998). "The life course as developmental theory." Child Development 69:1-12. https://doi.org/10.1111/j.1467-8624.1998.tb06128.x

Frank, K.A., Muller, C., Schiller, K.S., Riegle-Crumb, C., Mueller, A.S., Crosnoe, R., \& Pearson, J. (2008). The social dynamics of mathematics coursetaking in high school. American Journal of Sociology 113: 1645-96. https://doi.org/10.1086/587153

George, L.K. (1993). Sociological perspectives on life transitions. Annual Review of Sociology 19:353-373. https://doi.org/10.1146/annurev.so.19.080193.002033

Goldin, C., \& Katz, L.F. (2008). The race between education and technology. Cambridge, Mass., Harvard University Press.

Harris, K.M., Halpern, C.T., Whitsel, E., Hussey, J., Tabor, J., Entzel, P.,\& Udry, J.R. (2009). The National Longitudinal Study of Adolescent Health: Research Design. Retrieved June $5^{\text {th }} 2011$. (http://www.cpc.unc.edu/projects/addhealth/design).

Jacob B.A., \& Wilder, T. (2010). Educational expectations and attainment. NBER Work.Pap. No. 15683, Natl. Bur. Econ. Res. https://doi.org/10.3386/w15683 
Johnson, M.K., Crosnoe, R., \& Elder, G.H., Jr. (2011). Insights on Adolescence from a Life Course Perspective. Journal of Research on Adolescence 21: 273-80. https://doi.org/10.1111/j.1532-7795.2010.00728.x

Kroger, J. (2007). Identity development: Adolescence through adulthood. Thousand Oaks, CA: Sage. 2nd ed. Mirowsky, J., \& Ross, C.E. (2003). Education, social status, and health. New Brunswick, N.J.: Aldine Transaction. Muller, C., Pearson, J., Riegle-Crumb, C., Requejo, J., Frank, K., Schiller, K.S., Raley, R.K., Langenkamp, A.G., Crissey, S., Mueller, A.S., Callahan, R., Wilkinson, L., \& Field, S. (2007). National Longitudinal Study of Adolescent Health: Wave III Education Data. Chapel Hill: Carolina Population Center, University of North Carolina at Chapel Hill.

Muthén, L.K., \& Muthén, B.O. (1998-2006). Mplus user's guide. Fourth edition. Los Angeles, CA: Muthén \& Muthén.

Perreira, K.M., Deeb-Sossa, N., Harris, K.M., \& Bollen, K. (2005). What are we measuring? An evaluation of the CES-D across race/ethnicity and immigration generation. Social Forces 83: 1567-1602. https://doi.org/10.1353/sof.2005.0077

Rask, K. (2010). Attrition in STEM fields at a liberal arts college: The importance of grades and pre-collegiate preferences. Economic of Education Review, 29: 892-900. https://doi.org/10.1016/j.econedurev.2010.06.013

Reynolds, J.R., Stewart, M., MacDonald, R., \& Sischo, L. (2006). Have adolescents become too ambitious? High school seniors' educational and occupational plans 1976 to 2000. Social Problems, 53: 186-206. https://doi.org/10.1525/sp.2006.53.2.186

Reynolds, J. R., \& Baird, C. L. (2010). Is there a downside to shooting for the stars? Unrealized educational expectations and symptoms of depression. American Sociological Review, 75:151-172. https://doi.org/10.1177/0003122409357064

Riegle-Crumb, C., Muller, C., Grodsky, E., Langenkamp, A.G., \& Pearson, J. (2008). National Longitudinal Study of Adolescent Health: Wave III Education Data Post-Secondary. Chapel Hill: Carolina Population Center, University of North Carolina at Chapel Hill.

Schneider, B., \& Keesler, V.A. (2007). School reform 2007: Transforming education into a scientific enterprise. Annual Review of Sociology, 33:197-217. https://doi.org/10.1146/annurev.soc.33.040406.131731

Schneider, B., Swanson, C., \& Riegle-Crumb, C. (1997). Opportunities for learning: course sequences and positional advantages. Social Psychology of Education 2:25-53. https://doi.org/10.1023/A:1009601517753

Shouse, R.C. (1996). Academic Press and Sense of Community: Conflict and Congruence in American High Schools. Research in Sociology of Education and Socialization 11:173-202.

South, S., Haynie, D., \& Bose, S. (2007). Student mobility and school dropout. Social Science Research 36:68-94. https://doi.org/10.1016/j.ssresearch.2005.10.001

Staff, J., \& Kreager, D.A. (2008). Too cool for school? Violence, peer status and high school dropout. Social Forces 87:445-71. https://doi.org/10.1353/sof.0.0068

StataCorp. (2011). Stata statistical software: Release 12. College Station, TX: StataCorp LP.

Steinberg, L., Brown, B., \& Dornbusch, S. (1996). Beyond the classroom: Why school reform has failed and what parents need to do. New York: Simon \& Schuster. 